\title{
As novas perspectivas da imagem na era digital e os impactos na educação formal
}

\author{
Edemir José Pulita ${ }^{1}$ \\ Gilberto Lacerda dos Santos ${ }^{2}$
}

\section{Resumo}

Este artigo consiste no relato de uma investigação qualitativa, realizada com estudantes universitários de licenciaturas, que partiu do pressuposto de que as tecnologias digitais de informação, comunicação e expressão (TDICE) possibilitam novas formas de realizar as ações expressas no acrônimo informar, comunicar e expressar, calcadas cada vez mais no imagético. A finalidade foi a de levantar, junto aos licenciandos, elementos que contribuam para se avançar na compreensão dos novos aportes da imagem diante das TDICE, bem como eventuais impactos desses na educação formal. Os sujeitos produziram textos que, submetidos à análise de conteúdo, conduziram a uma categorização em três grupos: (a) novas perspectivas das imagens com mídias: relevância, rapidez e conexões; (b) modificações na educação formal pela cultura imagética com as tecnologias: construção de conhecimentos, ressignificação da escola e convergência midiática; (c) necessidade de um letramento visual para uma cultura imagética na escola da era digital: crítica à imagem, autonomia, polifonia e experiência.

Palavras-chave: Imagem. TDICE. Educação formal. Era digital. Letramento visual.

1 Programa de Pós-graduação em Educação - Universidade de Brasília.

2 Professor titular da Faculdade de Educação da Universidade de Brasília. 


\title{
The new perspectives of the image in the digital era and the impact on formal education
}

\begin{abstract}
This article is a report of a qualitative research conducted with university undergraduate students, who started from the assumption that digital technologies of information, communication and expression enable new ways of doing the actions expressed in the acronym - to inform, communicate and express - tamped increasingly in imagery. The purpose was to gather together the undergraduate, elements that contribute to advance understanding of the new contributions of the image on the technologies, and the potential impacts of these in formal education. The subjects produced texts that were submitted to content analysis, led to a categorization into three groups: (a) New perspectives of the media with images: relevance, speed and connections; (b) Changes in formal education by the image culture with technologies: building knowledge, school reframing and media convergence; (c) The need for visual literacy for an image culture in the school's digital age: critique of image, autonomy, polyphony and experience.
\end{abstract}

Keywords: Image. Technologies. Formal education. Digital age. Visual literacy.

\section{Introdução}

Sibilia (2012), em contundente análise da escola na Sociedade da Informação, classifica a situação como um cenário de "desencontros e fracassos", cuja consequência "costuma ser o tédio, a indiferença ou a frustração; em alguns casos, até a violência mais ou menos explícita" (SIBILIA, 2012, p. 79). Diante disso, perguntamo-nos: por que as novas gerações estão achando a escola enfadonha? A escola e as tecnologias são dispositivos que têm epistemologias, estruturas, 
funções e finalidades históricas constitutivamente diferentes, em termos de papéis, de momentos, de movimentos, de lugares e de processos. Assim, questionamos: como manejar os limites e os limiares entre adaptação, redução, didatização e conciliação desses universos? Se a escola tradicional pode ser vista como sinônimo de confinamento, de repressão e de opressão, também pode ser descrita como fonte de construção de conhecimentos e garantia da transmissão da cultura acumulada pela humanidade. Se as tecnologias podem significar conexão, compartilhamento e autonomia, também aprisionam, alienam e bitolam a consciência e a cidadania. Como encontrar, então, uma síntese entre regimes, lógicas e práticas que não se coadunam facilmente?

À luz dessas e de outras questões, realizamos uma investigação qualitativa, de natureza sócio-histórica (FREITAS, 2002), em que um grupo de futuros professores foi conduzido a elaborar verbalizações acerca desses desencontros e fracassos. A investigação relatada neste artigo se insere, portanto, no contexto das problematizações acerca das interfaces entre educação e tecnologias; refere-se às diferenças qualitativas entre os usos das tecnologias na educação formal e fora dela, e aponta para a necessidade de novas compreensões e propostas diante da cibercultura que se instala e que reconfigura os processos educativos, tecnológicos e comunicativos.

A título de introdução ao tema, ressaltamos que as telas, os teclados, os sistemas, as plataformas, os aplicativos e as conexões das tecnologias digitais transformam os fundamentos dos mecanismos de informação, de comunicação e de expressão em suas mais variadas dimensões e em seus mais diversos âmbitos. Dentre os vários aspectos que poderiam ser enfocados para problematizar tais questões, elegemos aqueles relacionados às imagens. Nesse sentido, partimos do pressuposto segundo o qual as tecnologias digitais de informação, de comunicação e de expressão (TDICE) possibilitam novas formas de realizar as ações expressas no acrônimo informar-se, comunicar-se e expressar-se, calcadas cada vez mais no imagético. A profusão tecnológica e as diferentes formas de sua apropriação possibilitam práticas comunicativas, informativas e expressivas nas quais a imagem passa a "competir" com o escrito em 
diversas instâncias e dimensões (SIBILIA, 2012, p. 63-64). Tais práticas afetam os processos de informação, de comunicação e de expressão dos sujeitos na sociedade em geral; portanto, demandam reflexão sobre suas repercussões na educação formal (SIBILIA, 2012, p. 65; 86; 90).

Diante disso, a finalidade da investigação relatada neste artigo foi a de levantar elementos que contribuam para se avançar na compreensão dos novos aportes da imagem diante das TDICE e analisar os eventuais impactos desses na educação formal. Nossa premissa é a da urgência de uma educação também visual diante de uma cultura imagética que se instala cada vez mais fortemente, revisando, dessa forma, o conceito de um letramento centrado na escrita.

Para dar forma à investigação, abordamos um grupo de 38 graduandos de licenciaturas - futuros professores em processo de formação inicial - e os envolvemos em uma dinâmica de coleta de dados estruturada em três momentos distintos e complementares: (1) leitura e discussão de textos provocadores sobre o tema em estudo; (2) visionamento e discussão de um filme problematizador do tema; (3) produção, pelos sujeitos da pesquisa, de textos reflexivos, decorrentes das discussões. Realizamos o procedimento de análise de conteúdo (BAUER, 2015) para a identificação de categorias explicativas nos textos produzidos e para a construção de respostas à questão norteadora da pesquisa: como as novas formas de produção, de circulação e de leitura de imagens, possibilitadas pelas TDICE, repercutem nos processos de informação, de comunicação e de expressão? E quais possíveis impactos isso tem na educação formal?

\section{Uma imagem vale por mil palavras?}

Se uma imagem vale mais do que mil palavras, então diga isto com uma imagem.

(Millôr Fernandes)

A expressão civilização da imagem nos aponta tanto para uma modalidade concreta de imagem visual, como a pintura, a fotografia e o vídeo, quanto para o fato de vivermos em um mundo no qual as imagens são cada vez mais numerosas, além de diversificadas e intercambiáveis entre seus suportes. Nesse sentido, ao tomarmos como ponto de partida 
essa expressão, procuramos considerar dois aspectos: (a) vivemos em uma civilização na qual, histórica e culturalmente, a imagem (de qualquer tipo) tem papel e valor fundamentais; e (b) as técnicas e as tecnologias atuais potencializam a produção, o acesso, o compartilhamento e a circulação de imagens.

O conceito de imagem está longe de ser unanimidade entre pesquisadores que o utilizam, e isso inclusive em áreas consideradas afins. Partimos, neste estudo, da conceptualização de Aumont (2014), quando afirma que "a imagem se define como um objeto produzido pela mão do homem, em determinado dispositivo, e sempre para transmitir a seu espectador, sob forma simbolizada, um discurso sobre o mundo real" (AUMONT, 2014, p. 272).

Porém, em contraponto, interessa-nos a problematização realizada por Flusser (2011), segundo a qual uma imagem é uma "superfície significativa na qual as ideias se inter-relacionam magicamente"; e, mais especificamente, imagem técnica diz respeito a uma "imagem produzida por aparelho" (FLUSSER, 2011, p. 12). Nesse sentido, concordamos com o autor, quando afirma que

[...] imagens são mediações entre homem e mundo. O homem 'existe', isto é, o mundo não lhe é acessível imediatamente. Imagens têm o propósito de lhe representar o mundo. Mas, ao fazê-lo, entrepõem-se entre o mundo e homem. Seu propósito é serem mapas do mundo, mas passam a ser biombos. O homem, ao invés de se servir das imagens em função do mundo, passa a viver em função das imagens. Não mais decifra as cenas da imagem como significados do mundo, mas o próprio mundo vai sendo vivenciado como conjunto de cenas. Tal inversão da função das imagens é idolatria. Para o idólatra - o homem que vive magicamente -, a realidade reflete imagens. (FLUSSER, 2011, p. 17, grifo do autor).

Essa abordagem de Flusser às questões da imagem lembra sobremaneira o conhecido mito da caverna platônico. Estaríamos repetindo a experiência dos personagens presos às sombras, porém, agora, em cavernas digitais? À pergunta "A imagem: uma civilização?", Aumont (2014) responde afirmando que, apesar da multiplicação de imagens visuais e de seus dispositivos e mídias de transmissão, "pode 
perceber-se hoje uma retomada da imagem através da multiplicação das imagens: mesmo assim, nossa civilização ainda continua a ser, quer se queira ou não, uma civilização da linguagem" (AUMONT, 2014, p. 328, grifo do autor).

Já para Flusser (2008), uma nova estrutura social, a qual ele denomina "sociedade da informática", está surgindo, ordenando "as pessoas em torno de imagens" (FLUSSER, 2008, p. 72). Essa organização se dá, segundo o autor, com duas tendências diferentes: “Uma indica o rumo da sociedade totalitária, centralmente programada, dos receptores das imagens e dos funcionários das imagens; a outra indica o rumo para a sociedade telemática dialogante dos criadores das imagens e dos colecionadores de imagens" (FLUSSER, 2008, p. 8).

Ao refletirmos sobre se estamos, de fato, vivendo numa civilização da imagem, parece-nos que uma questão imprescindível deve ser feita é: qual a relação entre a imagem e os suportes tecnológicos e digitais que atualmente maximizam sua produção, sua circulação e sua divulgação? Diante disso, ao se referir à imagem, Lévy (2007) afirma que "a cibercultura faz emergir uma nova forma e maneira de agir". Segundo o autor, no contexto atual, a imagem "perde sua exterioridade de espetáculo para abrir-se à imersão" (LÉVY, 2007, p. 149). Tais elementos apontam para uma nova relação com o saber que se modifica frente às novas possibilidades:

No lugar de uma representação em escalas lineares e paralelas, em pirâmides estruturadas em 'níveis', organizadas pela noção de pré-requisitos e convergindo para saberes 'superiores', a partir de agora devemos preferir a imagem de espaços de conhecimentos emergentes, abertos, contínuos, em fluxo, não lineares, se reorganizando de acordo com os objetivos ou os contextos, nos quais cada um ocupa uma posição singular e evolutiva (LÉVY, 2007, p. 158).

Nessa perspectiva, McLuhan (2007) faz uma comparação crítica entre o escrito e o imagético, ao afirmar que "a ênfase visual na continuidade, na uniformidade e no nexo sequencial, derivando da cultura letrada, leva-nos aos grandes meios tecnológicos de implementar a continuidade 
e a linearidade mediante a repetição fragmentada" (MCLUHAN, 2007, p. 375). A crítica é reforçada ao escrever:

Telefone: fala sem paredes.

Fonógrafo: music-hall sem paredes.

Fotografia: museu sem paredes.

Luz elétrica: espaço sem paredes.

Cinema, rádio, TV: sala de aulas sem paredes (MCLUHAN, 2007, p. 318).

Nessas novas articulações que se estabelecem entre imagens, tecnologias e diferentes formas de acesso, de construção e de circulação de conhecimentos, entrevemos a possibilidade de analisar e de questionar o atual modelo educacional a partir dos novos regimes de visibilidade e da cultura visual fortemente difundida pelas TDICE. Consoantes aos elementos trazidos por McLuhan, talvez essas articulações apontem para uma Educação: escola sem paredes.

\section{Interfaces entre imagens, TDICE e educação}

A cibercultura é definida por Rüdiger (2013) como "uma formação histórica de cunho prático e cotidiano, cujas linhas de força e rápida expansão, baseadas nas redes telemáticas, estão criando, em pouco tempo, um campo de interrogação intelectual pujante, dividido em várias tendências de interpretação" (RÜDIGER, 2013, p. 7). Na sequência, o autor escreve que "a revolução cibernética exige uma reestruturação dos programas e processos educacionais" (RÜDIGER, 2013, p. 8).

Refletindo sobre os modos de uso das TDICE na educação e fora dela, Sibilia (2012) afirma que "trata-se de uma tentativa de produzir a hibridação de dois regimes tão diferentes - inclusive contraditórios, ou até incompatíveis - como são o dispositivo pedagógico disciplinar e a conexão em redes informáticas" (SIBILIA, 2012, p. 190).

Já Costa (2005, p. 34), ao constatar a importância da leitura de imagens para a cultura humana, questiona: "por que a educação formal procura excluir a linguagem visual das atividades pedagógicas tão logo a criança se mostre medianamente alfabetizada? Por que a imagem se torna um 
elemento secundário na educação à medida que o aluno se alfabetiza?" (COSTA, 2005, p. 34). Ressaltando a necessidade de mudanças, afirma que "é nesse cenário que a educação tem que rever seu paradigma letrado e adentrar o campo das imagens e das linguagens tecnológicas para que possa ultrapassar as barreiras que separam duas culturas" (COSTA, 2005, p. 21).

Fazendo uma crítica semelhante, Ramal (2002) afirma que as imagens, no âmbito escolar, são usadas apenas "como simples ilustrações de textos verbais, utilizadas como explicadoras ou tradutoras de mensagens, quando não como mero adorno" (RAMAL, 2002, p. 56). A par dessa crítica à marginalização da imagem, a autora denuncia a roupagem modernizadora que a introdução da imagem, via TDICE, está tendo na escola, "nem sempre conseguindo superar o paradigma instrumental e mecanicista de ensino" (RAMAL, 2002, p. 57). E ainda:

Distante de grande parte das inovações tecnológicas do mundo contemporâneo, que têm no fenômeno da imagem uma de suas mais significativas expressões, até poucos anos a sala de aula era a mesma de décadas anteriores, espaço centrado na figura do professor e em suas explicações, com o auxílio de materiais didáticos muito parecidos entre si. [...] A escola continuou sendo o lugar da palavra, preenchido com atividades que supõem a escrita: copiar, transcrever, destacar, resumir... (RAMAL, 2002, p. 57).

No fluxo midiático digital, ocorre banalização e saturação, tanto das imagens quanto das palavras que, segundo Sibilia (2012), ao invés de propor ou garantir "experiências com seu peso capaz de marcar corpose subjetividades, elas patinam ou deslizam sem se prender a nada, [...] em vez de lhe dar espessura fazendo-a se deter ou interrompendo seu devir" (SIBILIA, 2012, p. 86, grifo nosso). Concluindo, a autora escreve que "em seu excesso sem densidade, tanto as imagens como as palavras se mostram impotentes para desacelerar esse fluxo ou para lhe dar coesão: não conseguem se condensar em diálogo nem em pensamento" (SIBILIA, 2012, p. 86, grifo nosso).

Já Ramal (2012) aponta a descontextualização tanto do texto quanto da imagem, ao criticar quando esses elementos, dentro da escola, são retirados "de sua função social viva, de seu contexto, de suas raízes e 
de sua história" (RAMAL, 2012, p. 58).

A crítica a respeito da falta de experiências significativas tanto com palavras quanto com imagens é reforçada por Tiburi (2011), ao escrever que "nosso analfabetismo é amplo, começa na escrita e chega à produção de imagens" (TIBURI, 2011, p. 38). Ainda segundo a autora, as ações de usar a Internet e de ver televisão deveriam ser as mesmas "de participar dela e construí-la" (TIBURI, 2011, p. 39).

Nova (2003), partindo da constatação da "centralidade das imagens no processo de constituição e raciocínio humanos", cita um "recalcamento da imagem no processo de construção do conhecimento efetuado pela ciência clássica" (NOVA, 2003, p. 192). Resumindo tais reflexões, concordamos com Nova (2003) acerca das novas compreensões possíveis dos limiares entre imagens e TDICE na educação da era digital:

Faz-se urgente o reconhecimento das imagens enquanto imagens estruturantes de um novo mundo. É necessário saber 'ler' essas novas imagens, para que elas não nos apareçam enquanto Franksteins. Esse é um dos papéis da educação desse novo milênio. Tarefa difícil, pois que vai de encontro a duas grandes bases de resistência. Uma primeira que é toda uma estrutura organizacional e burocrática da vida social, baseada nos modelos da escrita. Outra que se liga ao próprio ritmo de apreensão dessas imagens, dado que os milhões de estímulos ótico-sensoriais produzidos pelas imagens eletrônicas e digitais a cada dia dificultam e inibem a persistência de algum tipo de reflexão (NOVA, 2003, p. 191).

Por sua vez, Santaella (2012) apresenta propostas de se ensinar e de aprender a ler imagem, bem como aponta as múltiplas relações entre a imagem e o texto escrito. Um dos principais pressupostos do trabalho realizado pela autora é o de ressaltar a necessidade da expansão do conceito de leitura para além do texto escrito. Indicando uma mudança no regime de visibilidade atual, a pesquisadora afirma:

[...] a partir do advento da fotografia, na primeira metade do século XIX, as relações entre a imagem e a linguagem verbal escrita começaram a invadir cada vez mais o nosso cotidiano por meio de jornais, revistas, publicidade impressa e de rua. Municiado pelo desenvolvimento e sofisticação das tecnologias de impressão gráfica, o discurso verbal passou a ser entremeado com imagens 
em variadas combinatórias. Mais recentemente, com o surgimento da multi e hipermídia na internet, [...] as misturas entre imagens e texto estão tendendo a se tornar quase onipresentes. Essas misturas são tão exacerbadas nas diferentes mídias impressas, e agora também nas mídias digitais, que chegamos a nos esquecer que foi o livro o primeiro meio a dar acolhida aos intercâmbios de palavra e imagem (SANTAELLA, 2012, p. 106).

Os impactos dessas reflexões e mudanças podem ser sentidos e demandam respostas no campo da educação formal. Diante da profusão das tecnologias contemporâneas, Pretto e Pinto (2006) afirmam que é urgente a "demanda de novas educações, no plural", e apontam como características de tais mudanças "processos horizontais, processos coletivos, centros instáveis, currículo hipertextual, participação efetiva, formação permanente e continuada, simultaneidade entre a escrita e a oralidade, cooperação e sincronicidade na aprendizagem" (PRETTO; PINTO, (2006, p. 25).

Analisando as diferentes concepções sobre o uso de tecnologias na educação, Pretto (2011) ressalta um paradoxo, ao afirmar que "essas diferenças de concepção sobre o uso das tecnologias vêm trazendo sérios confrontos para a escola, fazendo com que os educadores vivam um verdadeiro impasse" (PRETTO, 2011, p. 108). Ao apontar as mudanças que estão em marcha, o autor escreve que "outros elementos passam a fazer parte dessas novas linguagens, com a intensificação do uso de símbolos, ícones e imagens, não mais como meras ilustrações de textos escritos" (PRETTO, 2011, p. 106).

Ao refletir sobre uma nova cultura de ensino e de aprendizagem com as tecnologias digitais, Kenski (2013) destaca que "a cultura contemporânea está ligada à ideia de interatividade, da interconexão e da inter-relação entre as pessoas, e entre essas e os mais diversos espaços virtuais de produção e disponibilização das informações" (KENSKI, 2013, p. 61). Frente a isso, conclui que essa nova cultura "exige a redefinição de papéis de alunos e de professores para que possam assumir novos comportamentos, condições de interação e valores socioeducacionais, diante do desafio de ensinar e aprender em tempos de mudanças" (KENSKI, 2013, p. 128). 
Diante desta ancoragem teórica, apresentamos, na sequência, a metodologia e a estruturação de uma pesquisa para se tentar avançar na reflexão acerca da temática.

\section{Parâmetros da pesquisa}

A investigação foi implementada em três semestres $\left(1^{\circ}\right.$ de 2013, e $1^{\circ}$ e $2^{\circ}$ de 2014), na disciplina Tópicos Especiais em Tecnologias Educacionais, ofertada pela Faculdade de Educação da Universidade de Brasília para estudantes de licenciatura. Ao todo, participaram da pesquisa 38 graduandos provenientes, em sua maioria, do curso de Pedagogia ( $\mathrm{n}=$ $29)$, e os demais, de outras Licenciaturas $(n=9)$.

Os aspectos teóricos discutidos na disciplina corresponderam, mantendo-se as devidas proporções quanto ao público e às finalidades do curso, aos tratados na fundamentação teórica deste artigo, como $O$ desmoronamento do sonho letrado: inquietação, evasão e Zapping e salas de aula informatizadas e conectadas: muros para quê?, ambos de Paula Sibilia (2012). Para contribuir com a reflexão também se assistiu ao filme Janelas da alma, de João Jardim e Valter Carvalho (2001), pelas provocações trazidas a respeito do olhar e das formas de utilização do imagético, a partir da apresentação de 19 casos de pessoas com algum tipo de problema visual.

Para fins de sigilo de identidade, os estudantes serão mencionados a partir de um código numérico. O primeiro número está relacionado à sua referência dentro da turma; o segundo número indica de qual das três ofertas da disciplina o mesmo participou. Por exemplo, a Estudante 06/02 é a sexta estudante da segunda experiência, ou seja, da turma do primeiro semestre de 2014.

A investigação foi realizada tendo como interlocutores e participantes professores em formação inicial. Diante das mudanças nos aparatos tecnológicos, das transformações em curso (modos de se comunicar, de se informar, de se expressar, de pensar, de ler e de escrever...), dos descompassos entre a difusão das tecnologias entre a sociedade e escola e das desconexões entre os usos de tecnologias na educação e fora dela, situamos a justificativa para tal estudo no fato de que justamente os 
futuros professores que atuarão nesse "caldo cultural" são sujeitos fundamentais, e precisam refletir e encontrar alternativas mais coerentes com a realidade e, principalmente, pensar tais questões centrando-se nas imagens.

A metodologia empregada foi uma pesquisa qualitativa de abordagem sócio-histórica, nos termos propostos por Freitas (2002), segundo os quais se busca a compreensão dos fenômenos particulares vistos como instâncias da totalidade social, uma vez que são enfocados em seu devir histórico. Ao refletir sobre tal abordagem, Jobim e Souza (2007) afirmam que a cultura da imagem deve ser estudada em profundidade, e que as imagens técnicas devem ser vistas "como instrumentos mediadores e reveladores das intensas experiências culturais e subjetivas que estamos vivendo no momento atual"' (JOBIM; SOUZA, 2007, p. 81).

Justificamos nosso método como o de pesquisa-ação, nos termos tratados por Thiollent (2011), pois, segundo o autor, os participantes desta pesquisa se reúnem para a resolução de problemas levantados conjuntamente, "ou, pelo menos, no avanço a ser dado para que sejam formuladas adequadas respostas sociais, educacionais, técnicas e/ ou políticas" (THIOLLENT, 2011, p. 7). Segundo o autor, "o principal objetivo consiste em oferecer ao pesquisador melhores condições de compreensão, decifração, interpretação, análise e síntese do 'material' qualitativo gerado na situação investigativa" (THIOLLENT, 2011, p. 35).

As aulas foram baseadas em discussões de textos teóricos referentes às temáticas propostas, à visualização e ao debate do filme, e motivadas por questionamentos e reflexões pertinentes às interfaces entre TDICE e educação formal. A partir desses recursos, os participantes produziram textos reflexivos, dentre os quais analisaremos aqueles referentes às discussões acerca das imagens. Utilizando-se da análise de conteúdos baseada na proposta por Bauer (2015, p. 191), que enfatiza a criação de núcleos de significação em torno das citações mais frequentes e pertinentes, foram formuladas, após exaustivas leituras do material recolhido e da seleção de citações, quatro categorias que julgamos coerentes com a finalidade de construção de respostas ao objetivo e à questão norteadora da pesquisa. 


\section{Com a palavra, os participantes da pesquisa!}

Diversas citações fazem menção às mudanças das ações de se informar, comunicar-se e se expressar viabilizadas pelas TDICE, o que gerou a primeira categoria elaborada: Relações entre mudanças possibilitadas pelas TDICE e a constituição de um novo regime de visibilidade e dimensões do imagético. As mudanças citadas são expressas pelo Estudante 12/01 (2013), quando afirma que "o conceito de cultura digital ainda está em construção e parte da ideia de que a revolução das tecnologias digitais faz parte da cultura e é capaz de mudar o modo como as pessoas se comportam". O estudante citado afirma que tais modificações impactarão a educação, e que "isto significa, que o aprendizado com essas novas mídias será um exercício constante nas diferentes áreas do conhecimento" - Estudante 12/01 (2013).

A Estudante 07/02 (2014) escreve que, atualmente, "vive-se em um mundo onde a experiência comunicativa se dá de forma audiovisual, onde imagens são geradas e apresentadas a todo o momento, em um curto espaço de tempo". Fazendo uma análise do impacto do atual regime imagético na sociedade, ela aponta que "o excesso de imagens disponibilizados em um curto espaço de tempo tira a atenção e extingue os sentimentos produzidos por elas, impossibilitando que a sociedade sinta incomodo real com o que lhes é apresentado pelas mídias" Estudante 07/02 (2014). Nesse mesmo sentido, outra graduanda cita o que ela chama de uma "cegueira generalizada que a sociedade tem vivido devido às imagens prontas que a nós são fornecidas em revistas, em folders, em jornais, na internet, na televisão, nos livros didáticos etc." (ESTUDANTE 09/02, 2014). Da mesma forma, a Estudante 13/02 (2014) afirma que "a grande quantidade de imagens constrói um olhar superficial das pessoas sobre as informações".

Ao fazer a pergunta "Quais são as verdadeiras consequências desta revolução da imagem?", a Estudante 03/03 (2014) materializa o que pretendemos caracterizar como a segunda categoria: As TDICE e as novas formas de produção, de circulação e de leitura de imagens. Ao afirmar que "vivemos numa sociedade conectada, num fluxo constante de imagens 
e informações. Para usarmos dessas tecnologias, tivemos que aprender novas formas de ser, estar, observar e sentir", a Estudante 06/03 (2014) sintetiza diversas outras declarações dos demais graduandos, ao escrever:

Dentre os novos estímulos que acompanharam as novas tecnologias, destacamos aqui as imagens. Elas assumiram um papel de destaque no nosso cotidiano, sendo constantes na televisão, nos computadores, tabletes, celulares, câmeras digitais, dentre diversos outros dispositivos. Nós nos relacionamos com as imagens o tempo todo, produzindo-as, observandoas e compartilhando-as. O contato com as imagens faz parte da forma como temos experimentado o mundo na sociedade contemporânea. (ESTUDANTE 06/03, 2014).

Diversos elementos são apontados também pelo Estudante 08/03 (2014), ao afirmar que "com essas tecnologias, o acesso a redes sociais ficou muito mais fácil e rápido. Através de alguns aplicativos como WhatsApp e o Facebook a troca de imagens e vídeos é intensa e instantânea". O papel das TDICE na relação com as imagens é expresso pelo Estudante 12/01 (2013), ao escrever que “a cultura imagética tem como característica a visualização de imagens e permite a criação de diversos conceitos e concepções". Sintetizando a reflexão, uma graduanda apresenta a seguinte crítica:

Partindo desta questão sobre a dispersão, podemos pensar sobre o bombardeio de imagens à que somos, de modo geral, expostos todos os dias. As mídias, com seus avanços tecnológicos, fazem com que as informações cheguem a nós em uma velocidade cada vez maior, instantânea. Fatos ocorridos ao redor do mundo estão acessíveis ao simples clique. São fotos, vídeos, áudios... Este caos informacional acaba nos anestesiando, e adquirimos uma 'cegueira' momentânea, isto é, nos tornamos insensíveis para determinados fatos. (ESTUDANTE 13/03, 2014).

Diante da constatação das novas formas de produção, de leitura e de circulação de imagens, possibilitadas pelas TDICE, e da modificação das formas de apropriação, de percepção e de difusão de como as pessoas em geral lidam com o imagético, diversos participantes da pesquisa demonstraram preocupação com os impactos que isso terá na 
educação formal. Vemos, nessa transposição de reflexão, a construção da terceira categoria: As imagens na educação e a educação das/nas/pelas/para as imagens. Por exemplo, quando o Estudante 13/03 (2014) escreve que "o que fica de exemplo e de mensagem, é que através da educação do olhar, somos capazes de nos tornar, mesmo nesse turbilhão do mundo atual, novamente sensíveis aos fatos que merecem destaque". Ou, ainda, quando a Estudante 13/02 (2014) afirma que as TDICE possibilitaram mudanças "nos conceitos, no olhar e nas práticas educacionais da atualidade. Os impactos dessas mudanças trouxeram um novo prisma no processo de construção do conhecimento, na aprendizagem, na relação da escola com os alunos, e do aluno com o professor". Essa estudante complementa:

\begin{abstract}
A grande quantidade de informações através das imagens trouxe uma anestesia em relação a este fato, onde as pessoas não refletem criticamente sobre essas informações que são colocadas a todo o momento. A agilidade da informação, a cultura das imagens, muito maior do que da escrita, o contato das pessoas muitas vezes mais por meios tecnológicos do que pessoalmente, o trabalho como fator central das relações, trouxe um novo olhar da vida, impôs uma ressignificação dos processos de leitura, oralidade e escrita e essa nova dinâmica trouxe uma necessidade de se repensar os processos educacionais. (ESTUDANTE 13/02, 2014).
\end{abstract}

A aluna 09/02 (2014) destaca que "diante dessa função de mediar e de incentivar o olhar do discente que a Educação agregar, a Tecnologia pode ser vista como um suporte a equipe escolar, como uma janela que permite a visão além dos muros da escola". E afirma que "o Ensino passará a ser contextualizado (e não 'floreado') a partir do momento que a tecnologia passar a ser um aliado da Educação" (ESTUDANTE 09/02, 2014). Lembrando o risco da ineficácia da mera inserção das imagens e das tecnologias na escola, sem uma revisão mais profunda dos elementos e dos fatores envolvidos, a Estudante 10/02 (2014) afirma que "a escola se torna incompatível com a realidade em que vivemos e logo não tem atrativo para que o aluno a frequente. Ele sente necessidade de ser sujeito ativo e participativo e abandonar a condição de espectador". Essa estudante conclui: 
[...] é preciso pensar na ressignificação das práticas pedagógicas para não utilizar esta ferramenta de maneira antiga, pois o simples ato de levar as redes sociais para a estrutura arcaica da escola não provocará mudanças. As mídias tradicionais e a educação bancária nunca ensinaram como olhar, pois privilegiam a percepção [...]; e cabe à escola e especialmente aos professores direcionar as informações para que os conhecimentos não sejam somente absorvidos, mas que sejam produzidos, compartilhados e 'curtidos'. (ESTUDANTE 10/02, 2014).

A Estudante 07/03 (2014) parte de argumentos muito semelhantes, ao afirmar que "vivencia-se a civilização da imagem, mas a escola ainda persiste em utilizar a palavra como principal, e na maioria das vezes único, meio de comunicação. Com a vigência deste método os jovens se sentem desmotivados a freqüientarem as aulas". Segundo ela, "inserir a imagem como forma de comunicação dentro do ensino escolar é uma solução a ser estudada. Formular um novo método para que haja mudanças significativas na leitura e interpretação imagética pode gerar mudanças nos índices de analfabetismo" (ESTUDANTE 07/03, 2014).

Seguindo uma argumentação muito semelhante, a Estudante 06/02 (2014), também conclui que "apenas a 'maneira tradicional' de se estudar, com leitura e uso de livros por exemplo, não tem estimulado e atraído os alunos de hoje, o professor precisa de estratégias para atrair os alunos".

Já a Estudante 08/02 (2014) afirma que a escola precisa reconhecer seus erros e derrubar seus muros, introduzindo as tecnologias e suas perspectivas, "porém, a tão sonhada adequação entre esses dois meios, não deve limitar-se a usar a tecnologia como recursos didáticos, é preciso ensinar a lidar com a tecnologia, produzir condições de recepção e agir sobre os efeitos dispersivos". Nesse sentido, a Estudante 13/02 (2014) escreve: "Acredito que o desafio dessa nova geração de professores e também dos antigos, que podem sempre se reciclar, é descobrir maneiras novas de estimular os alunos a se interessarem pelo que é proposto dentro da escola". Da mesma forma, a Estudante 01/03 (2014) argumenta que a escola está "sendo sufocada diante do avanço das linguagens audiovisuais, onde a sala de aula tem se transformado em algo chato e o fato de freqüentá-la é uma tortura para o dinamismo dos jovens 
modernos". Para tanto, propõe que

[...] o primeiro passo está sendo equipar os colégios com tecnologia de ponta, mas não se pode parar logo no primeiro passo já que a inserção de novas ferramentas não garante o sucesso de atualização do ensino para acomodar novos paradigmas. Nem os computadores, a internet, tablets e celulares são recursos 'neutros', máquinas não são boas nem más já que carregam consigo uma série de valores e modos de uso implícitos. (ESTUDANTE 01/03, 2014).

Nesse ínterim, o professor tem um papel essencial:

[...] o professor não deve assumir um papel tecnofóbico com total aversão às novas tecnologias, sustentando-se no temor de vir a ser substituído pela máquina ou, de que de algum modo, esta venha a destruir as ligações afetivas humanas. Contudo, não deve também pensar que a máquina venha a resolver todos os problemas modernos. O papel do professor é apresentar aos alunos uma nova realidade. (ESTUDANTE 03/03, 2014).

Da mesma forma, a Estudante 14/01 (2013) afirma que "o computador e a internet tornaram-se indispensáveis para a pesquisa, comunicação e informação, proporcionando constante troca de conhecimentos, e possibilitando o aperfeiçoamento de práticas pedagógicas". Especificamente sobre as mudanças possibilitadas pelas TDICE e sua relação mais geral com a educação formal, entrevemos uma importante síntese na fala de uma graduanda, ao afirmar:

[...] para concluir, não podemos esquecer a linguagem mais utilizada no nosso dia a dia, a Linguagem Digital. A muitos conflitos ao se discutir como deveriam ser incluídas essas tecnologias no ambiente escolar. Mas o papel da escola é ensinar a aprender e para tanto ela deve acompanhar as transformações que estão se processando do lado de fora da sala de aula para enriquecer o processo ensino aprendizagem nas diferentes linguagens existentes. Então não podemos apontar a melhor ou pior linguagem, os professores devem saber utiliza-las dentro de sala de aula conforme os objetivos que são pretendidos. Saber interagir com as diversas linguagens gera enriquecimento para o desenvolvimento do processo de aprendizagem dos alunos. Lembrando que cada Linguagem apresenta suas particularidades e 
devem ser utilizadas para que haja interação entre aluno-professor (ESTUDANTE 15/01, 2013).

Diante da premente necessidade de se inserir a imagem com um novo status no contexto escolar, duas problemáticas emergem das reflexões dos estudantes. Uma é expressa pelo Estudante 02/03 (2014), ao perguntar: "E como a escola está reagindo ou agindo com essa mudança toda?". A segunda é manifestada pela Estudante 08/03, ao questionar: "Seria possível fazer com que os professores que são de outra época se adaptem a essa nova realidade dos jovens e faça com que seja possível a construção do conhecimento?". Tais questões nos apontam para a Necessidade de um letramento visual para uma cultura imagética, nossa quarta categoria, que é introduzida pela Estudante 02/03 (2014), ao afirmar que

[...] hoje as escolas precisam melhorar e se atualizar em relação as novas tecnologias, mas também melhorar o convívio aluno professor, não se prender em só dar o conteúdo que se foi elaborado, não condicionando o aluno só aprender o que o professor ensina, tentar despertar o interesse dos alunos, buscando novos métodos de ensino, trazendo o aluno para a escola, para que eles não vejam a escola como uma cadeia (ESTUDANTE 02/03, 2014).

A Estudante 13/02 (2014) parte da constatação de que "as crianças dessa nova geração, já nascem cercados de uma quantidade de imagens muito grande, são a geração das mídias". Diante disso, aponta a necessidade de novos modelos educativos, pois os "métodos que não acompanharem esse novo fluxo, precisam ser revistos sob uma nova ótica, pois como consequência de tudo isso, o significado da escola mudou e o papel do professor também foi ressignificado" (ESTUDANTE 13/02, 2014).

Nesse sentido, a Estudante 14/03 (2014) afirma que a utilização das imagens na educação "pode ser enxergada como conhecimento a ser desenvolvido, e uma linguagem a ser expressa e refletida". Segundo a graduanda, "é possível compreender a importância de trabalhar com a imagem, não como um complemento, mas sim como fonte de conhecimento" (ESTUDANTE14/03, 2014). Por sua vez, outra estudante 
alerta sobre a inserção, tanto das tecnologias em geral quanto das imagens em particular, poder somente mascarar pretensas mudanças, pois, dessa forma, "apenas está havendo uma mudança nos meios, porem a educação continua com as mesmas bases, não alterando assim a forma como esse estudo e transmitidos" (ESTUDANTE 10/03, 2014).

Nesse mesmo diapasão, a Estudante 13/02 (2014) parte da crítica de que "a superficialidade desse olhar, fruto de uma cultura de imagens aleatórias e sem crítica alguma, traz essas consequências para dentro da sala de aula, propondo um desafio para o professor de desconstruir ou reconstruir o processo educativo". Diante disso, a graduanda aponta que "a situação atual pede que se insira na sala de aula a cultura hipertextual, para que se propicie a aproximação da educação com o aluno que temos hoje" (ESTUDANTE 13/02, 2014). Falando sobre a necessidade de um letramento visual para uma cultura imagética, essa aluna afirma que "não podemos deixar de lado o letramento e suas funções óbvias para o processo educativo, mas não cabe mais deixar de lado necessidades que cada vez mais vem se impondo" (ESTUDANTE 13/02, 2014).

\section{Conclusões}

A problematização da imagem proposta na investigação realizada exemplifica uma das mudanças em marcha nas formas de informação, de comunicação e de expressão diante das TDICE. Aponta ainda como tais mudanças chegam à escola e impactam a educação formal, entre outros aspectos; mostra que a questão não é só introduzir a imagem, seja por quais meios e formatos forem, sem dar importância para uma modificação das linguagens, mantendo as mesmas lógicas e finalidades da educação tradicional e bancária, como a memorização descontextualizada e a aprendizagem sem sentido nem contexto. Nesse sentido, consideramos que não será a mera instrumentalização de aparatos tecnológicos ou a simples utilização aleatória de imagens nos processos da educação formal que fará diminuir as desconexões e os descompassos atualmente existentes.

Pela análise de dados realizada, constata-se a importância da reflexão 
da temática geral das interfaces entre educação e tecnologias e, mais especificamente, das questões da imagem nesse contexto, principalmente com futuros educadores. Estes licenciandos estabelecem relações entre as mudanças possibilitadas pelas TDICE e a constituição de um novo regime de visibilidade, apontando para novas formas de produção, de circulação e de leitura de imagens diante das mídias atuais. Esses futuros professores ainda indicam elementos significativos das imagens na educação, e apontam para a urgência de uma educação das, nas, pelas e para as imagens, bem como sugerem a necessidade de um letramento visual para uma cultura imagética.

Para responder ao objetivo do trabalho e à pergunta inicial, a partir da análise dos dados realizada, elaboramos uma categorização das novas perspectivas da imagem possibilitadas pelas TDICE e seus impactos na educação formal, em três grupos. Em cada categoria, apontamos os elementos constituintes e sinalizamos a que se referem, de acordo com as citações dos participantes da pesquisa.

\section{I - Novas perspectivas das imagens com TDICE}

- Relevância: sinalizações sobre a pertinência da cultura imagética, conforme expresso pelos participantes 01/03 (2014), 03/03 (2014), 07/03 (2014) e 06/02 (2014).

- Rapidez: sinalizações sobre a efervescência da cultura imagética, consoante ao sugerido pelos participantes 12/01 (2013), 14/01 (2013), 07/02 (2014), 13/02 (2014), 08/03 (2014) e 13/03 (2014).

- Conexões: sinalizações sobre a imagem como ponte/link para a realidade e o contexto dos sujeitos da educação, de acordo com os participantes 08/02 (2014), 09/02 (2014), 13/02 (2014) e 07/03 (2014).

\section{II - Modificações na educação formal pela cultura imagética com as TDICE}

- Construção de conhecimentos: sinalizações em torno de novas formas de ensinar e de aprender, em conformidade ao enunciado 
pelos participantes 08/01 (2013), 12/01 (2013), 14/01 (2013), 09/02 (2014), 13/02 (2014), 08/03 (2014), 13/03 (2014) e 14/03 (2014).

- Ressignificação da escola: sinalizações em torno da necessidade de se repensar a escola, segundo os participantes 14/01 (2013), 10/02 (2014), 13/02 (2014), 01/03 (2014), 02/03 (2014), 03/03 (2014) e 08/03 (2014).

- Convergência midiática: sinalizações para a necessidade de diversificação das linguagens (e mídias) na escola, como apontado pelos participantes 14/01 (2013), 15/01 (2013), 07/03 (2014) e 10/03 (2013).

\section{III - Necessidade de um letramento visual para uma cultura imagética na escola da era digital}

- Crítica à imagem: sinalizações sobre a profusão desenfreada de imagens, que pode gerar "anestesia" ou "cegueira", conforme escreveram os participantes 07/02 (2014), 09/02 (2014), 13/02 (2014) e 13/03 (2013).

- Autonomia: sinalizações sobre a imagem como mobilizadora e libertadora do sujeito, de acordo com os participantes 03/02 (2014), 06/02 (2014), 10/02 (2014), 13/02 (2014), 02/03 (2014), 03/03 (2014) e 07/03 (2014).

- Polifonia: sinalizações sobre a imagem como geradora de dissensos, consoante ao aludido pelos participantes 07/02 (2014), 13/02 (2014), 03/03 (2014) e 10/03 (2013).

- Experiência: sinalizações sobre a necessidade e as possibilidades de novas experiências com imagens na educação, em conformidade com o referido pelos participantes 08/01 (2013), 14/01 (2013), 03/02 (2014), 07/02 (201), 13/02 (201), 06/03 (2014) e 13/03 (2014).

Ao nos referirmos a tais elementos, imagens, TDICE e educação, o episódio envolvendo uma imagem que teve grande repercussão em uma questão de uma prova de Filosofia, envolvendo a artista Valesca Popozuda, citada como "grande filósofa contemporânea", merece ser mencionado. Fazemos tal referência pelo fato de uma participante 
da pesquisa fazer estágio no mesmo colégio e no mesmo período do fato, o que gerou grande debate reflexivo com os demais estudantes. Também para apontar como a mídia deu ampla difusão a uma imagem fotográfica falsa, propositadamente criada e divulgada em consenso entre o professor e os alunos como uma forma de protesto. O motivo da criação da questão, de ela ser fotografada e de sua divulgação foi o fato de que, semanas antes, o professor e os alunos haviam realizado um trabalho com produção de fotografias e uma exposição, porém, ao chamarem jornalistas para a divulgação, não foi dada nenhuma cobertura por parte da mídia. Diante da frustração gerada nos alunos, e em acordo com eles, o professor propôs a elaboração dessa situação que gerou manchetes nacionais. Diante disso tudo, a participante da disciplina concluiu:

Por fim, diante do exposto afirmo que a experiência é o caminho para a inovação. A partir do conhecimento que o professor Kubitschek adquiriu durante seus 49 anos de vida e 19 de docência, ele não se 'acomoda' em uma metodologia 'prática e fácil de ministrar' e não utiliza os recursos tecnológicos como um instrumento neutro. Mas usa das adversidades para impor novas metas, para criar possibilidades de diálogo - comunicação (ESTUDANTE 09/02, 2012).

Dos elementos apresentados e desse exemplo, consideramos a importância de discussão mais ampla sobre a profusão informacional, comunicativa e expressiva possibilitada pelas tecnologias, em especial, a atualidade da reflexão acerca das questões envolvendo as imagens diante das TDICE. Para além das questões enfatizadas neste estudo sobre as novas perspectivas da imagem oriundas da profusão midiática na era digital e de seus impactos na educação formal, bem como a problemática da formação dos profissionais que atuarão nesse "caldo cultural", sugerimos a necessidade de aprofundamento de tais elementos em termos didáticos e metodológicos específicos, dentro de cada campo e de cada disciplina de atuação, e ainda nas diferentes fases do processo educacional. Pela natureza da disciplina e da heterogeneidade dos participantes na pesquisa realizada, essa personalização não foi possível.

Os impactos das novas perspectivas da imagem com as mídias digitais na educação formal apontam para novas imagens possíveis e necessárias 
da escola na era digital. Imagens essas que, diante das mudanças e das transformações, exigem novas reflexões e práticas, e apontam outros olhares e letramentos possíveis e necessários.

\section{Referências}

AUMONT, J. A imagem. Tradução de Estela dos Santos Abreu e Cláudio C. Santoro. Campinas, SP: Papirus, 2012.

BAUER, M. W. Análise de conteúdo clássica: uma revisão. In: BAUER, M. W.; GASKELL, George (Org.). Pesquisa qualitativa com texto, imagem e som: um manual prático. Tradução de Pedrinho A. Guareschi. 13. ed. Petrópolis, RJ: Vozes, 2015. p. 189-217.

COSTA, C. Educação, imagem e mídias. São Paulo: Cortez, 2005.

ESTUDANTE 08/01. Texto reflexivo. Brasília, DF, 11 junho 2013.

ESTUDANTE 12/01. Texto reflexivo. Brasília, DF, 11 junho 2013.

ESTUDANTE 14/01. Texto reflexivo. Brasília, DF, 11 junho 2013.

ESTUDANTE 15/01. Texto reflexivo. Brasília, DF, 11 junho 2013.

ESTUDANTE 03/02. Texto reflexivo. Brasília, DF, 24 março 2014.

ESTUDANTE 06/02. Texto reflexivo. Brasília, DF, 24 março 2014.

ESTUDANTE 07/02. Texto reflexivo. Brasília, DF, 24 março 2014.

ESTUDANTE 08/02. Texto reflexivo. Brasília, DF, 24 março 2014.

ESTUDANTE 09/02. Texto reflexivo. Brasília, DF, 24 março 2014.

ESTUDANTE 10/02. Texto reflexivo. Brasília, DF, 24 março 2014.

ESTUDANTE 13/02. Texto reflexivo. Brasília, DF, 24 março 2014. 
ESTUDANTE 01/03. Texto reflexivo. Brasília, DF, 30 setembro 2014.

ESTUDANTE 02/03. Texto reflexivo. Brasília, DF, 30 setembro 2014.

ESTUDANTE 03/03. Texto reflexivo. Brasília, DF, 30 setembro 2014.

ESTUDANTE 06/03. Texto reflexivo. Brasília, DF, 30 setembro 2014.

ESTUDANTE 07/03. Texto reflexivo. Brasília, DF, 30 setembro 2014.

ESTUDANTE 08/03. Texto reflexivo. Brasília, DF, 30 setembro 2014.

ESTUDANTE 10/03. Texto reflexivo. Brasília, DF, 30 setembro 2014.

ESTUDANTE 13/03. Texto reflexivo. Brasília, DF, 30 setembro 2014.

ESTUDANTE 14/03. Texto reflexivo. Brasília, DF, 30 setembro 2014.

FLUSSER, V. O universo das imagens técnicas. São Paulo: Annablume, 2008 .

Filosofia da caixa preta: ensaios para uma futura filosofia da fotografia. São Paulo: Annablume, 2011.

FREITAS, M. T. A. A abordagem sócio-histórica como orientadora da pesquisa qualitativa. Cadernos de Pesquisa, São Paulo, n. 116, p. 21-39, jul. 2002. Disponível em: <http:/ / www.scielo.br/scielo.php?script=sci_ arttext\&pid=S0100-15742002000200002\&lng=en\&nrm=iso $>$. Acesso em: 21 abr. 2016.

JANELA da alma. Direção: Jaime Jardim e Walter Carvalho. São Paulo: Estúdio Europa Filmes, 2001. (73 minutos).

JOBIM E SOUZA, S. Dialogismo e alteridade na utilização da imagem técnica em pesquisa acadêmica: questões éticas e metodológicas. In: FREITAS, M. T.; JOBIM E SOUZA S.; KRAMER, S. (Org.). Ciências humanas e pesquisa: leituras de Mikhail Bakhtin. 2. ed. São Paulo: 
Cortez, 2007. p. 77-94.

KENSKI, V. M. Tecnologias e tempo docente. Campinas, SP: Papirus, 2013.

LÉVY, P. Les Technologies de l'intelligence: L'avenir de la pensée à l'ère informatique. Paris: La découverte, 1990.

Cibercultura. Tradução de Carlos Irineu da Costa. São Paulo: Editora 34, 2007.

MCLUHAN, M. Os meios de comunicação como extensões do homem. Tradução de Décio Pignatari. São Paulo: Cultrix, 2007.

NOVA, C. Imagem e educação: rastreando possibilidades. In: ALVES, L.; NOVA, C. (Org.). Educação e Tecnologia. Salvador: Editora da UNEB, 2003. p. 180-196.

PRETTO, N. O desafio de educar na era digital: educações. Rev. Port. de Educação, Braga , v. 24, n. 1, p. 95-118, 2011. Disponível em: <http:/ / www.scielo.mec.pt/scielo.php?script=sci_arttext\&pid=S087191872011000100005\&lng=pt\&nrm=iso > . Acesso em: 21 set. 2015.

PRETTO, N. PINTO, C. C. Tecnologias e novas educações. Revista Brasileira de Educação, Rio de Janeiro, v. 11 n. 31, p. 19-30, jan./abr. 2006. Disponível em: <http://www.scielo.br/pdf/rbedu/v11n31/a03v11n31. pdf>. Acesso em: 10 ago. 2015.

RAMAL, A. C. Educação na cibercultura: hipertextualidade, leitura, escrita e aprendizagem. Porto Alegre: Artmed, 2002.

RANCIÈRE, J. O destino das imagens. Tradução de Mônica Costa Netto. Rio de Janeiro: Contraponto, 2012.

RÜDIGER, F. As teorias da cibercultura: perspectivas, questões e autores. Porto Alegre: Sulina, 2013. 
SANTAELLA, L. Leitura de imagens. São Paulo: Melhoramentos, 2012.

SIBILIA, P. Redes ou paredes: a escola em tempos de dispersão. Tradução de Vera Ribeiro. Rio de Janeiro: Contraponto, 2012.

THIOLLENT, M. Metodologia da pesquisa-ação. 18. ed. São Paulo: Cortez, 2011.

TIBURI, M. Olho de vidro: a televisão e o estado de exceção da imagem. Rio de Janeiro: Record, 2011. 